\title{
Functional resistance and resilience of the pore system of an andisol exposed to different strategies of pasture improvement under sheep grazing
}

\author{
J. Ivelic-Sáez ${ }^{1.2}$, F. Zúñiga ${ }^{2,4}$, S. Valle ${ }^{3,4}$, I. López ${ }^{4,5}$, D. Dec ${ }^{3,5}$, J. Dörner ${ }^{3,4}$ \\ ${ }^{1}$ Instituto de Investigaciones Agropecuarias, INIA-Kampenaike. Punta Arenas, Chile \\ ${ }^{2}$ Magister en Ciencias del Suelo, Escuela de Graduados, Facultad de Ciencias Agrarias, Universidad \\ Austral de Chile, Valdivia, Chile. ${ }^{3}$ Instituto de Ingeniería Agraria y Suelos, Facultad de Ciencias Agrarias, \\ Universidad Austral de Chile, Valdivia, Chile. ${ }^{4}$ Centro de Investigación en Suelos Volcánicos, Universidad \\ Austral de Chile, Valdivia, Chile. Instituto de Producción Animal, Facultad de Ciencias Agrarias, \\ Universidad Austral de Chile, Valdivia,Chile.Corresponding autor: jorge.ivelic@inia.cl,josedorner@uach.cl
}

\begin{abstract}
In southern Chile, different strategies have been utilized to improve the production levels of degraded pastures. Due to grazing, soils are subjected to mechanical and hydraulic stresses throughout the year. The aim of the study was to evaluate the effect of different strategies to improve a degraded naturalized pasture under sheep grazing on the resistance and resilience of the pore system of an Andisol subjected to mechanical and hydraulic stresses. Undisturbed soil samples were collected from two tilled, seeded and fertilized pastures (T1-T2), a non-tilled degraded and naturalized pasture with no fertilization (T3), a fertilized pasture (T4) and a non-tilledfertilized and ungrazed pasture (T5). Also, cylinders were filled with homogenized soil (T6). The tilled and non-tilled pastures (T1-T5) were able to maintain their functions of storage and transport of water and air as well as their mechanical properties against both stresses. No significant differences between the pasture improvement strategies were observed when evaluated during the second year after the implementation of the improvement strategies, which highlights the high resistance and resilience capacity of the Andisol. However, some tendencies (e.g. while the air capacity and permeability tended to increase following mechanical stress, plant available water increased; the opposite was observed following hydraulic stress) and significant differences (due to the simulated effect of aggregate destruction during tillage, a decrease in air capacity, and an increase in soil shrinkage capacity after compaction were assessed) were observed, which highlight the necessity for further studies to better understand the complex interactions in pasture systems.
\end{abstract}

Keywords: Soil mechanical strength, porous system, pasture improvement management, volcanic ash soil 


\section{Introduction}

One of the main agricultural activities in southern Chile is livestock production. In this part of the country, where pastures are the main source for cattle and sheep feeding soils are predominantly derived from volcanic ashes (CIREN, 2003). It has been assessed that $91 \%$ of the 1.3 million hectares of pastures are naturalized and at least $75 \%$ of them have some degree of degradation, which is reflected by low soil fertility (levels of aluminum saturation $>$ $15 \%$ and P-Olsen $<3 \mathrm{ppm}$ ) and negative changes in soil functions like decreases in water holding capacity (Zuñiga et al., 2015) with negative productive, social and environmental consequences. To improve livestock production in a pasture based system, it is relevant to establish strategies to improve the condition of the degraded pastures. These strategies include fertilizing pastures on untilled degraded soils as well as the establishment of new pastures by tilling and fertilizing the soil. The study of the impact of both techniques on the physical functioning of soil is relevant since it is recognized that volcanic soils have excellent physical properties, e.g. low bulk density, high water storage capacity and hydraulic conductivity (Dörner et al., 2010 b), which may be deteriorated depending on the intensity of land use and soil management (Dörner et al. 2013 a).

Pasture improve techniques have different impacts on the soil's physical quality (Zúñiga et al., 2015). On the other hand, animal trampling during grazing causes external stresses on the soil altering its structure and pore functions (Reszkowska et al., 2011). Thus, the physical quality of soils can be studied based on two concepts: the soil's physical resistance and its resilience (Gregory et al., 2009). While the first is the ability of the soil to maintain its functions after compaction, the second is defined as the ability of the soil to recover its pore functions after removing the stress. This is relevant in soils derived from volcanic ashes in southern Chile, since livestock production systems are based on pastures, which are grazed throughout the year, leaving the soil exposed to the effect of external pressures caused by grazing animals, and internal stresses due to wetting and drying cycles (Dec et al., 2012). While the first type of stress (animal trampling) can cause compaction, negatively affecting soil structure and its physical functions like hydraulic conductivity (Reszkowska et al., 2011), the internal stress allows the soil to recover its functions like air conductivity due to crack formation (Dörner $e t$ al., 2011, Dec et al., 2012).

The soil's physical resistance and resilience have been investigated considering a soil property before and after the stress is applied. Resistance has been evaluated in Andisols under native forest, pasture and crop rotation once the soil has been compacted (Ellies et al., 1993), in Cambisols and Luvisols in England under similar managements (Gregory et al., 2009), and Cambisols, Regosols and Luvisols in Scotland under forest plantations, pastures and mountainous terrain (Kuan et al., 2007). Resilience has been quantified by characterizing the recovery of soil porosity after compaction (Zhang et al., 2005). Ellies et al. (1993) indicate that strength of an Andisol (Typic Hapludand) is related to the intensification of land use. They reported that soils under crops, when compared to those under native forest, are mechanically more resistant as a consequence of the destruction and subsequent consolidation of aggregates, which is further accentuated when the soil water content is reduced, due to a stronger cohesion between aggregates. Furthermore, Gregory et al. (2009) emphasize that physical resistance and 
resilience are largely dependent on the amount of organic matter, which is reflected in higher microbial activity and better rooting, for example, in a pasture system. A higher content of organic matter allows for a rebound effect against mechanical stresses and also promotes soil structure formation (Chenu and Consentino, 2011), therefore, it is less likely that the soil will be affected by mechanical and hydraulic stresses, and in fact, the recovery of soil functions is enhanced (Dörner et al., 2011).

The effect of grazing on the structure and physical quality of the soil has been evaluated in Andisols (e.g. Dec et al., 2012). However, the effect of different strategies to improve degraded pastures on the resistance and resilience of the soil's physical functions has not been analyzed. The latter is relevant, since tillage, for example, breaks down the soil structure diminishing pore functions (Zuñiga et al., 2015), e.g. after tillage the air capacity can decrease from $14.9 \%$ (initial situation of a naturalized pasture subjected to 30 years of extensive grazing) to $5.5 \%$ (seeded pasture of Lolium perenne and Trifolium repens and grazed by sheep), while non-tilled and fertilized soils maintain and may even improve some physical parameters (e.g. air permeability changed from $1.0 \log \mu \mathrm{m}^{2}$ to $2.5 \log \mu \mathrm{m}^{2}$ ) in the short term (Dörner et al., 2013b). Thus, the hypothesis was that after subjecting the soil to mechanical (e.g. animal trampling) and hydraulic (wetting and drying cycles) stresses, the porous systems in soils with a nondisturbed structure is stronger and more resilient than those of soils where the structure has been modified by tillage, and even more than those of completely homogenized soils. Therefore, the aim of this study was to analyze the effect of different improvement strategies for a degraded naturalized pasture under sheep grazing on the resistance and resilience of the porous system.

\section{Materials and Methods}

\subsection{Soil and management}

The study was conducted at the Universidad Austral de Chile's Austral Agricultural Research Station, Valdivia, Chile (39 $48^{\prime}$ 'S, $73^{\circ} 15^{\prime}$ E, 12 m.a.s.l). The soil corresponded to an Andisol (Duric Hapludand, CIREN, 2003 according to Soil Survey Staff, 2006) Series Valdivia. The soil has a silty loam texture in the first horizon $(0-30 \mathrm{~cm})$ becoming coarser with depth, with textures from sandy loam to sand $(30-120 \mathrm{~cm})$. The organic matter content was about $14.4 \%$ in the first horizon, decreasing with depth until reaching $2.5 \%$ in the last horizon (Dörner et al., 2013a). A detailed description of the physical properties of the studied soil under different managements and land uses can be found in Dec et al. (2012), Dörner et al. (2013a, b) and Zúñiga et al. (2015). The climate is temperate rainy with marine influence, with an average annual temperature of $12.1^{\circ} \mathrm{C}$ and an average rainfall of $2300 \mathrm{~mm}$.

The experiment was performed on degraded pastures with a residence time of 30 years. Six treatments (Table 1) were considered and arranged as a complete randomized block design with 3 blocks (15 plots of $20 \times 20 \mathrm{~m}$ ). Two seeded pastures were used: mixed binary species of Lolium perenne and Trifolium repens (T1) and multiple species mixture (T2) composed of Bromus valdivianus, Holcus lanatus, Lolium perenne, Dactylis glomerata and Trifolium repens. To seed the pastures, the soil was firstly tilled by using a ploughing disc followed by the use of an off-set disc (3 times). A vibrocultivator was then used, and finally a roller compactor was applied once. After soil tillage, the pastures were seeded. In addition, untilled pastures were also considered, one corresponded to a non-fertilized naturalized degraded pasture (T3) and 
the other was a fertilized naturalized degraded pasture (T4), both initially composed of Agrostis capillaris, Hypochaeris radicata, Anthoxanthum odoratum, and Rumex acetocella. Additionally, an exclusion site was studied, which had not been grazed for three years (T5), and disturbed soil from the degraded naturalized pastures was collected to prepare cylinders of homogenized soil to simulate the effect of loss of structure by tillage (T6). The summary of the treatments, management and botanical composition is shown in Table 1.

Table 1. Soil management and botanical composition of pasture improvement strategies.

\begin{tabular}{|c|c|c|}
\hline Treatment & Soil Management & Botanical Composition \\
\hline T1 & $\begin{array}{l}\text { Tilled soil, fertilized when sown, } \\
\text { grazed }\end{array}$ & Lolium perenne and Trifolium repens \\
\hline $\mathbf{T 2}$ & $\begin{array}{l}\text { Tilled soil, fertilized when sown, } \\
\text { grazed }\end{array}$ & $\begin{array}{l}\text { Bromus valdivianus, Holcus lanatus, } \\
\text { Lolium perenne, Dactylis glomerata and } \\
\text { Trifolium repens }\end{array}$ \\
\hline T3 & $\begin{array}{l}\text { Non-tilled, unfertilized, grazed } \\
\text { (initial situation) }\end{array}$ & $\begin{array}{l}\text { Agrostis capillaris, Hypochaeris radicata, } \\
\text { Anthoxanthum odoratum, and Rumex } \\
\text { acetocella }\end{array}$ \\
\hline T4 & Non-tilled, fertilized, grazed & $\begin{array}{l}\text { Agrostis capillaris, Hypochaeris radicata, } \\
\text { Anthoxanthum odoratum, and Rumex } \\
\text { acetocella }\end{array}$ \\
\hline T5 & $\begin{array}{l}\text { Non-tilled, unfertilized, ungrazed } \\
\text { (initial situation) }\end{array}$ & $\begin{array}{l}\text { Agrostis capillaris, Hypochaeris radicata, } \\
\text { Anthoxanthum odoratum, and Rumex } \\
\text { acetocella }\end{array}$ \\
\hline T6 & $\begin{array}{l}\text { Soil tillage simulation by soil } \\
\text { sieving at } 2 \mathrm{~mm}\end{array}$ & None \\
\hline
\end{tabular}

All pastures (except T5 and T6) were intensively grazed according to herbage mass and pasture height. A grazing event started when the pasture herbage mass was between 2200 and $2500 \mathrm{~kg} \mathrm{DM} \mathrm{ha}^{-1}$ and finished when the residual herbage mass reached between 1000 and $1400 \mathrm{~kg} \mathrm{DM} \mathrm{ha-1.} \mathrm{Grazing} \mathrm{was}$ conducted with a stocking density of 625 sheep ha-1. The maximum grazing frequency was 60 days, having this criteria priority over the available herbage mass. Further details regarding the management of the grazed pastures can be found in Dörner et al. (2013a) and Zúñiga et al. (2015). 


\subsection{Field sampling and laboratory sample preparation}

Soil samples were collected in September 2011, the second year of pasture establishment. Eighteen cylinders (h: $5.6 \mathrm{~cm}, \mathrm{~d}: 7.2 \mathrm{~cm}$, volume: $230 \mathrm{~cm}^{3}$ ) of undisturbed soil were collected between 1 and 8 cm depth after removing the topsoil (T1 to T5). The cylinders were covered with metal lids and wrapped up with polypropylene plastic sheets to prevent soil disturbance and evaporation. Enough disturbed material was extracted from the same site and soil depth as the treatment samples to fill 18 cylinders with a bulk density of $0.7 \mathrm{Mg} \mathrm{m}^{-3}$ (T6), which corresponded to the average density of the soil for all treatments.

The disturbed material was dried at $30^{\circ} \mathrm{C}$, then sieved to $2 \mathrm{~mm}$. The soil was applied on the inside of the cylinder in $4 \mathrm{~cm}$ sheets, then each sheet was pressed gently until the soil reached a bulk density of $0.7 \mathrm{Mg} \mathrm{m}^{-3}$.

\subsection{Laboratory analysis}

In order to determine the performance of the soil porosity before applying both stresses as well as to analyse the effects of these perturbations on soil physical functions, the water retention curve (WRC), soil shrinkage curve and air conductivity were measured before and after the stresses. Firstly, a water retention curve (WRC) (cycle 1, $\mathrm{C}_{1 ;} \mathrm{n}=9$ per treatment and per stress) equilibrating the soil samples at $0,-1$, $-2,-3,-6,-15,-33,-50 \mathrm{kPa}$ of matric potential was determined (from -1 to $-6 \mathrm{kPa}$ sand tanks were used and from -15 to $50 \mathrm{kPa}$ by pressure chambers); the weight was recorded at each point using an electronic balance (Precisa 1000C-3000D, precision $0.01 \mathrm{~g}$ ), while the one-dimensional deformation (shrinkage) was registered with an electronic caliper (Insize series 1141, precision $0.01 \mathrm{~mm}$ ). Furthermore, within a matric potential range of -6 to $-50 \mathrm{kPa}$, the air conductivity $\left(k_{l}\right)$ was measured with an airflow meter (Dörner and Horn, 2006). Once the first water retention curve was finished, the soil cylinders were saturated with water from beneath. Thereafter, the samples were drained and equilibrated again at matric potential $-6 \mathrm{kPa}$ and soil weight, shrinkage and $k_{l}$ were measured. At this stage, the mechanical (MS) and hydraulic (HS) stresses were applied. For MS, soil samples were subjected to a mechanical pressure of $80 \mathrm{kPa}$ (using a piston odometer), and for HS, the samples were equilibrated at $-80 \mathrm{kPa}$ of matric potential (via pressure chambers, the same used for the determination of the water retention curve). This pressure was selected in both stresses because it is within the range of pressure produced by a sheep hoof on the ground (Krümmelbein et al., 2006).

Mechanical stress consisted of 6 minutes of loading and 6 minutes of unloading. During that time the samples reached a maximum deformation at $80 \mathrm{kPa}$ pressure and a maximum recovery once the stress was removed (which was tested before implementing the experiment), where the one-dimensional deformation of the soil was measured and, subsequently, the water content and $k_{l}$. The hydraulic stress consisted of equilibrating the soil samples at $-80 \mathrm{kPa}$ of matric potential. This was accomplished in 14 days (which was tested before implementing the experiment) and later, the water content, $k_{l}$ and vertical deformation of the soil due to shrinkage were measured.

Finally, once the application of both types of stresses had ended, the samples were equilibrated again until water saturation was reached $(0 \mathrm{kPa})$ and a second WRC (Cycle 2, $\mathrm{C}_{2}$ ) was determined by registering the same variables used in the first cycle $\left(\mathrm{C}_{1}\right)$. After the last WRC, the cylinders were dried at $105^{\circ} \mathrm{C}$ for 48 hrs to record their weight and height. 


\subsection{Evaluation of the porous system before and after} the stresses

The evaluation of the porous system was conducted considering capacity and intensity parameters according to Horn and Kutilek (2009). As capacity parameters air capacity (AC), volume of plant available water (PAW) and shrinkage indexes (COLE and PSI) were considered, while as intensity parameters (Horn and Kutilek, 2009) air permeability $\left(k_{a}\right)$ and porous continuity indexes $\left(k_{2}\right.$ and $\left.k_{3}\right)$ were evaluated.

Both AC and PAW were obtained from the water retention curve, after correcting their values according to soil shrinkage (Dörner et al., 2010b). Both parameters were calculated as follows:

$$
\begin{aligned}
& \mathrm{AC}=\theta_{0 \mathrm{kPa}}-\theta_{6 \mathrm{kPa}} \\
& \mathrm{PAW}=\theta_{6 \mathrm{kPa}}-\theta_{1543 \mathrm{kPa}}
\end{aligned}
$$

Where $\theta$ corresponded to volumetric water content $(\%)$ at a given tension.

On the other hand, air permeability $\left(k_{a}\right)$ was calculated from air conductivity $k_{l}\left(\mathrm{~cm} \mathrm{~s}^{-1}\right)$ according to the following formula (Dörner and Horn, 2006):

$$
k_{a}=\frac{k_{l} * n}{\rho l * g}
$$

Where, $\eta$ is the viscosity of air $\left(\mathrm{g} \mathrm{s}^{-1} \mathrm{~cm}^{-1}\right), \rho_{1}$ is the density of air $\left(\mathrm{kg} \mathrm{m}^{-3}\right)$ and $g$ is the acceleration of gravity $\left(\mathrm{m} \mathrm{s}^{-1}\right)$. Both viscosity and air density were corrected for $\mathrm{T}\left(\mathrm{C}^{\circ}\right)$.
Pore continuity was determined using two indexes of continuity proposed by Groenevelt et al. (1984) and used by Dörner and Horn (2006) and Reszkowska et al. (2011). These indexes are calculated from the relationship between air permeability $\left(k_{a}\right)$ and air-filled porosity $\left(\varepsilon_{a}\right)$ and the relation between $k_{a}$ and ${ }_{a}^{2}$.

$$
k_{2}=\frac{k_{a}}{\varepsilon_{a}}
$$

$$
k_{3}=\frac{k_{a}}{\varepsilon_{a}{ }^{2}}
$$

Groenevelt et al. (1984) mentioned that soils with similar pore size distribution and porosity continuity have analogue values of $k_{2}$. Furthermore, soils with similar values of $k_{3}$ have only similar pore size distribution. Therefore, different values of $k_{2}$ and $k_{3}$ are due to differences only in the continuity of pores, independent of pore size distribution (Groenevelt et al., 1984; Dörner and Horn, 2006).

To determine the shrinkage curve, moisture $(\vartheta)$ and void $(e)$ indexes were calculated as follows:

$$
\vartheta=\frac{V_{w}}{V_{s}} \quad\left(\mathrm{~m}^{3} \mathrm{~m}^{-3}\right)
$$

$$
e=\frac{V_{f}}{V_{s}} \quad\left(\mathrm{~m}^{3} \mathrm{~m}^{-3}\right)
$$

where $V_{w}, V_{f}$ and $V_{s}$ are water, pore and solids volume (Dörner et al., 2009b). 
The coefficient of linear extensibility (COLE), which defines the one-dimensional deformation of the soil from a water saturation point to dry conditions (Dörner et al., 2009b), was defined as follows:

Where $\mathrm{L}_{0 \mathrm{kPa}}$ and $\mathrm{L}_{6 \mathrm{kPa}}$, are the height of the sample at $0 \mathrm{kPa}$ and the height of the sample at $6 \mathrm{kPa}$ tension, respectively.

The shrinkage capacity can be defined by the pore shrinkage index (PSI), which relates to the volume of soil that shrinks $\left(\Delta \mathrm{V}_{\mathrm{f}}\right)$, regarding the loss of water volume $\left(\Delta \mathrm{V}_{\mathrm{w}}\right)$ when an increase in water stress in the soil is applied (Dörner et al., 2009b).

\subsection{Statistical analyses}

The normality of the data was evaluated with the Shapiro-Wilks Test $(p \leq 0.05)$, and the homogeneity of variance by the Levene Test $(p \leq 0.05)$. When the data did not represent a normal distribution, they were $\log$-transformed or were presented in box diagrams. Two-way ANOVA $(p<0.05)$ were used to analyze statistical differences between treatments, cycles and factors and their eventual interaction. Differences between mean treatments were analyzed by using the Tukey test $(\mathrm{p}<0.05)$. The standard error of the means was used as a dispersion parameter.

\section{Results}

3.1. Effect of mechanical and hydraulic stresses on the soil pore functions

Figure 1 (a and c) shows soil air capacity (AC) for the different treatments exposed to mechanical (MS) and hydraulic (HS) stresses. Two years after tillage, when comparing the seeded pastures ( $\mathrm{T} 1$ and T2) with the non-tillage pastures (T3, T4 and $\mathrm{T} 5)$, the first showed lower values of AC although only significant for the first WRC $\left(\mathrm{C}_{1}\right.$ in Figure 1c). After MS (Figure 1a), there was a reduction of the fraction of air-filled pores in all treatments (second WRC, $\mathrm{C}_{2}$ ), but it was statistically significant only in the soil under the ungrazed excluded pasture (T5), which had the highest AC while T2 (seeded pasture) had the lowest AC. The opposite occurred for HS that showed a trend, although non-significant $(p=0.7538)$, towards increasing $\mathrm{AC}$ post-stress $\left(\mathrm{C}_{2}\right)$. The volume of plant available water (PAW) can be observed in Figure 1 ( $b$ and $d)$. On average, for the different types of stress, soils under different pastures present values of PAW ranging from 22\% (T3 and T4) to $36 \%$ (T1 and T2), with the homogenized soil reaching the highest values (approximately 40\%). After MS there was no significant effect on PAW ( $p=0.1699$ ); however, all structured soils showed a trend towards a slight increase in the volume of plant available water. On the other hand, after the application of HS there was a trend towards decreasing PAW in $\mathrm{C}_{2}$, being highly significant in T6 (Figure 1d). 

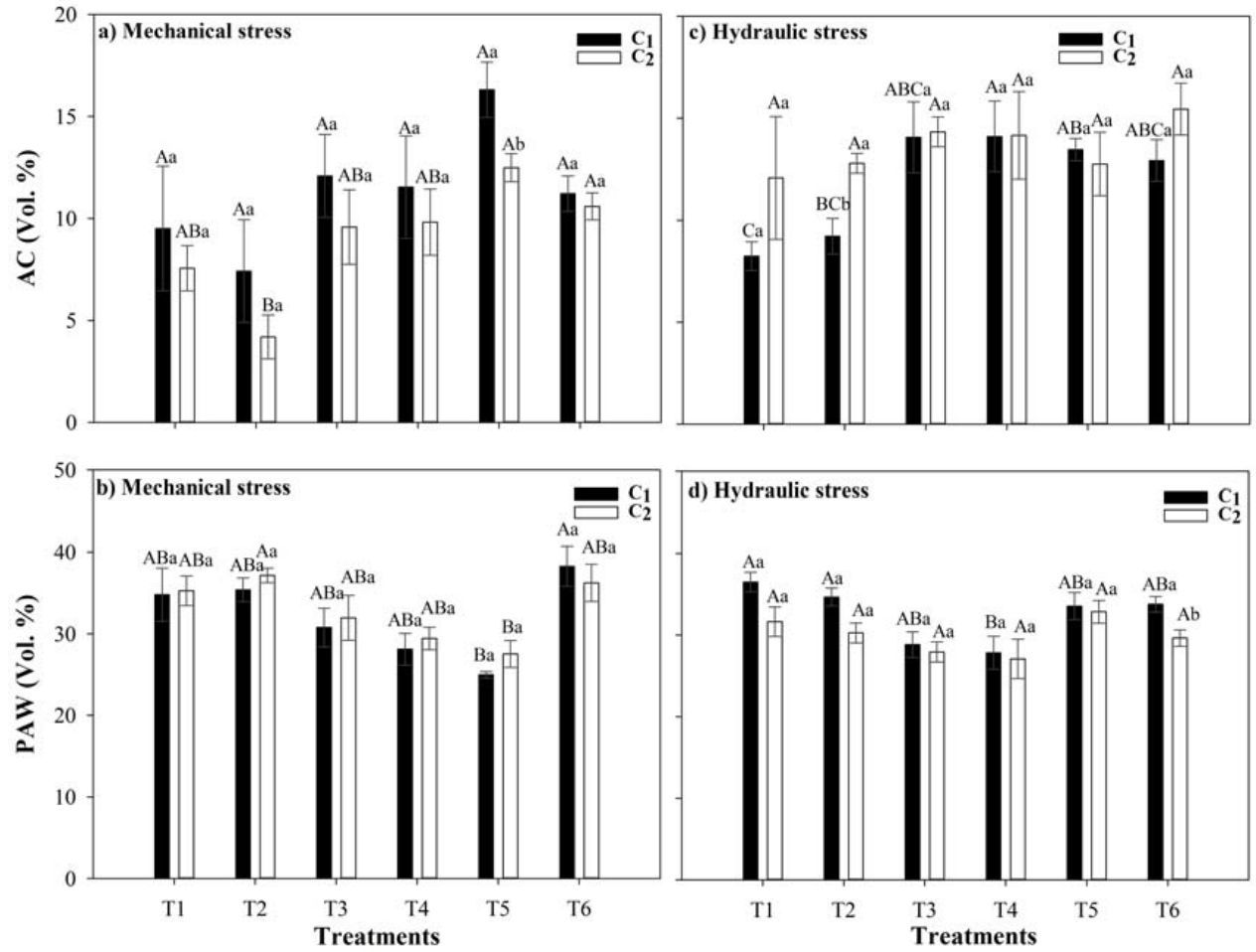

Figure 1. a) Air Capacity (AC) and b) Plant Available Water (PAW) under mechanical stress. c) AC and d) PAW, under hydraulic stress. Capital letters indicate differences between treatments for each cycle $(p<0.05)$. Lowercase letters indicate difference between cycles for each treatment $(p<0.05)$. Bars indicate \pm 1 standard.

The air permeability values $\left(k_{a}\right)$ for the treatments undergoing both types of stresses are shown in Figure 2. Overall, the trend in the behavior of $k_{a}$ was maintained among the samples used for mechanical and hydraulic stresses, with statistically significant differences being only observed between soils exposed to HS in $\mathrm{C}_{1}(\mathrm{~T} 4$ and $\mathrm{T} 6>\mathrm{T} 1)$. On the other hand, the effect of the application of the MS appears as a decrease in $k_{a}$ (except T1, although not significant), being significant $(p<0.05)$ in T5 and highly significant in T6 $(\mathrm{p}<0.01)$. By contrast, the effect of the HS does not show a clear trend, but there is still a highly significant increase of $k_{a}$ in T6. 

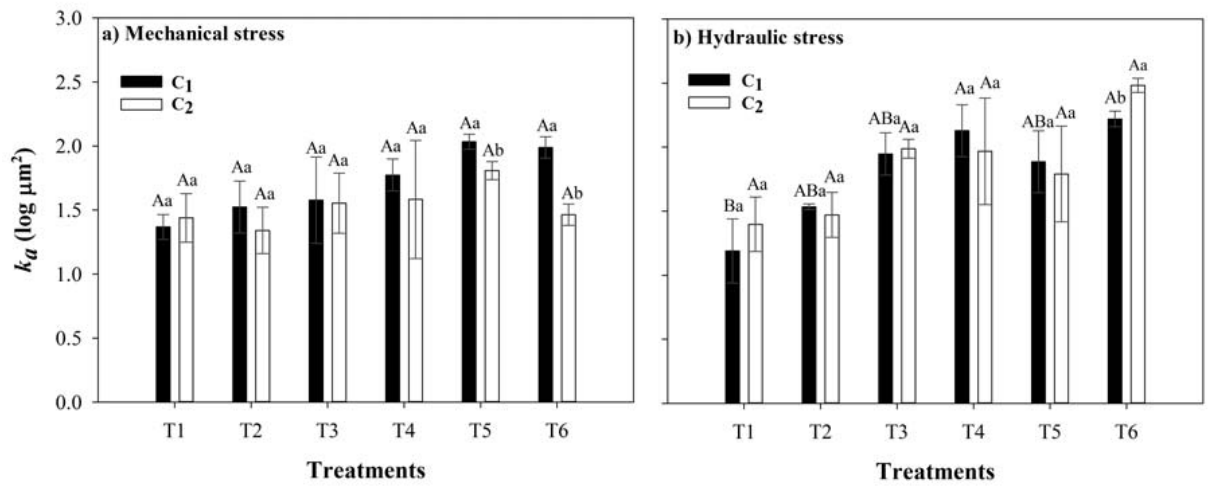

Figure 2. Air Permeability $\left(k_{a}\right)$ under a) mechanical and b) under hydraulic stresses. Capital letters indicate differences between treatments for each cycle $(p<0.05)$. Lowercase letters indicate difference between cycles for each treatment $(p<0.05)$. Bars indicate \pm 1 standard.

Figure 3 shows the continuity indices $\left(k_{2}\right.$ and $\left.k_{3}\right)$ of macropores (0 to $-6 \mathrm{kPa}$ matric potential) for MS and HS registered during the first $\left(\mathrm{C}_{1}\right)$ and second $\mathrm{WRC}\left(\mathrm{C}_{2}\right)$. The $k_{2}$ index for the MS does not show a clear trend in data distribution. However, a tendency could be observed for the HS where untilled pastures (T3, T4 and T5) and T6 showed higher values. There were no clear differences between treatments for the $k_{3}$ index subjected to MS. Finally, if comparing continuity rates $\mathrm{T} 6$ was the only one that showed significant differences between mechanical stress cycles, where values decrease for $\mathrm{C}_{2}$. Meanwhile $k_{3}$ showed a similar trend to $k_{2}$, with no differences in either cycles after the MS. Still, there was an effect for T6, where the index decreases significantly. However, for the HS there were significant differences only for continuity indexes in $\mathrm{C}_{2}$, with no differences between cycles for any of the treatments.

Figure 3. Box plots for pore continuity indexes: a) $k_{2}$ and c) $k_{3}$ under mechanical stress, as well as: b) $k_{2}$ and d) $k_{3}$ under hydraulic stress of macropores. 
The mechanical behavior of the soil during both stresses is expressed through the coefficient of linear extensibility (COLE). The effect of the different treatments on soil mechanical stability, showed highly significant differences in the COLE during the first WRC $\left(C_{1}\right)$ for the samples used in the MS (Figure 4a). After this stress, the samples that kept their structure (T1 to T5) showed an increase of COLE (this being significant to T2), whereas this parameter decreased $(\mathrm{p}<0.01)$ in homogenized samples $(\mathrm{T} 6)$. The soil exposed to HS only showed a significant reduction of COLE in T6 (Figure 4).

Non-tilled pastures (T3-T5) had a lower pore shrinkage index (PSI) compared to those pastures subjected to mechanical perturbation (T1, T2 and T6). Even though this was not statistically significant $(p=0.1835)$, a tendency was observed for both HS and MS (Figure 4b-d). Still, there was a significant decrease of the PSI in completely homogenized soil after the application of both stresses.
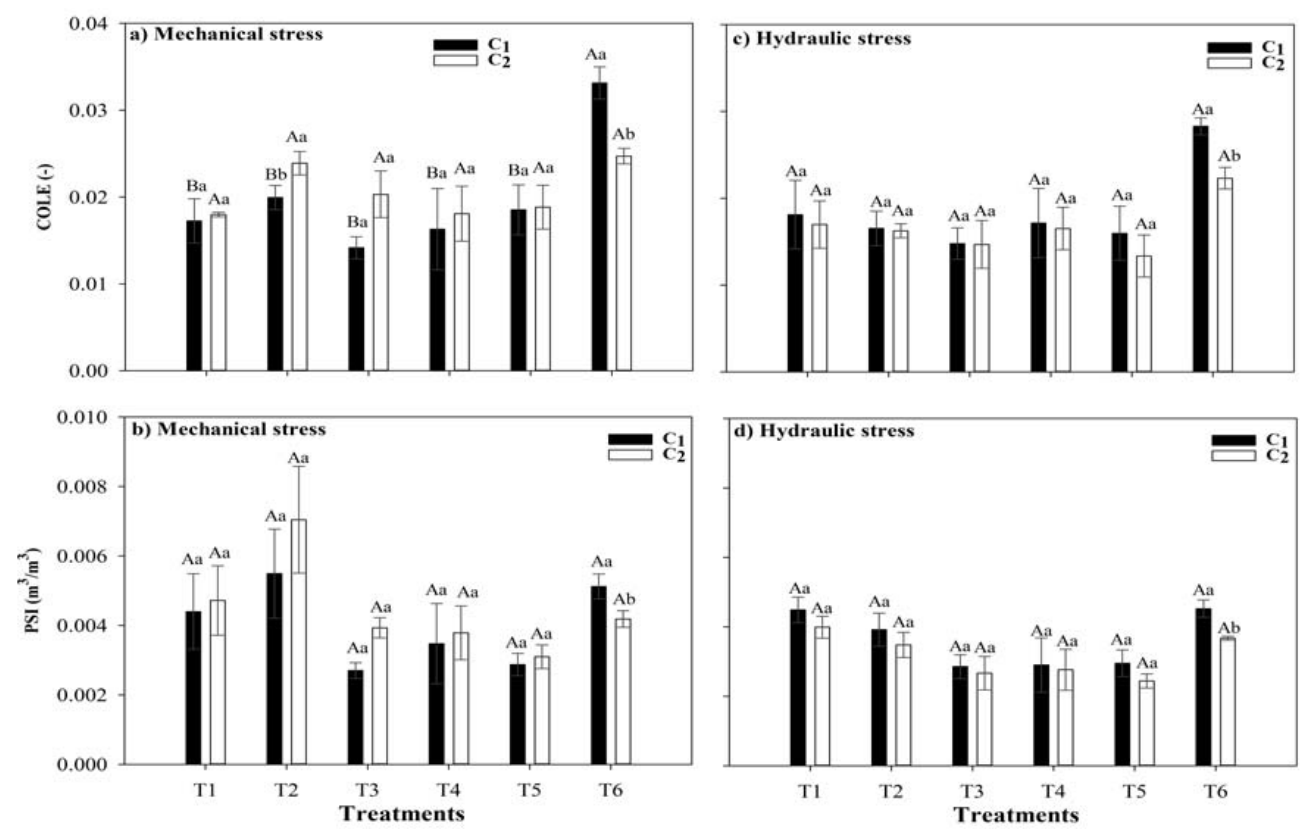

Figure 4. a) Coefficient of linear extensibility (COLE) and b) Pore Shrinkage Index (PSI) of macropores (0-6 kPa tension) under mechanical stress. c) COLE and d) PSI of macropores under hydraulic stress. Capital letters indicate differences between treatments for each cycle $(p<0.05)$. Lowercase letters indicate differences between cycles for each treatment $(p<0.05)$. Bars indicate \pm 1 standard. 


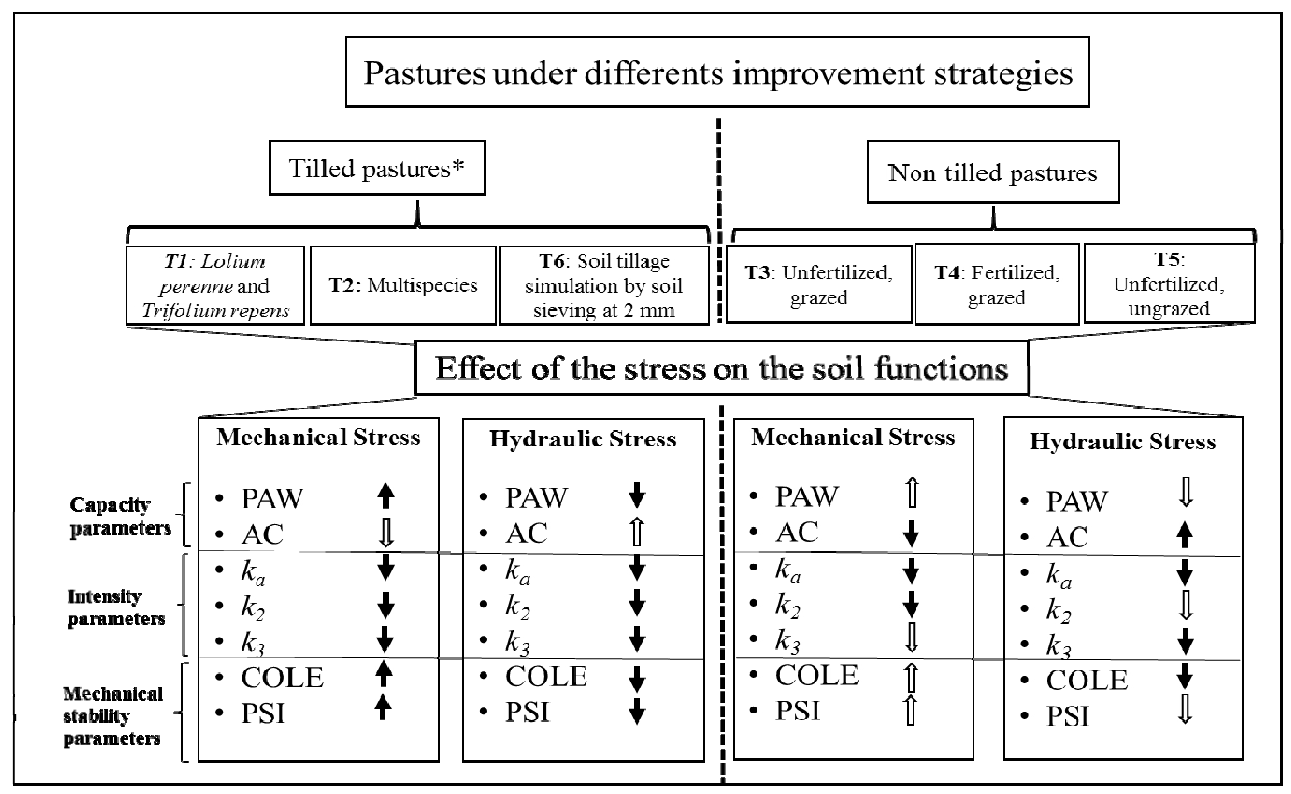

Figure 5. Schematic representation of the effect of mechanical and hydraulic stresses on the pore system of the soil under tilled ( 2 years-old) and untilled pastures subjected to sheep grazing. Black arrows indicate a change with a greater magnitude, whereas white arrows show a change with lower magnitude when comparing tilled and untilled pastures.

\section{Discussion}

According to current literature, the scientific community is not only concerned about the effect of the change in soil management on soil physical properties (e.g. Reszkowska et al., 2011 and Gan et al., 2012), but also on the resistance and resilience of the resource after stressing events (Dörner et al., 2009b; Gregory et al., 2009). This is highly important in order to determine the ability of the soil to recover its functions, such as air capacity and water storage capacity (Dörner et al., 2009b), which becomes even more relevant considering the current scenario: an increased pressure on natural resources (soil and water) and the potential consequences of climate change (Gan et al., 2012).

\subsection{Effect of mechanical and hydraulic stresses on the functions of the pore system of the soil}

The decrease in macroporosity (AC) due to MS (e.g. animal trampling, traffic of heavy machines) has been reported in Andisols of Chile (Dörner et al., 2009a, b, 2011). The same effect was reported on Calcic Chernozem soils under intensive and extensive sheep grazing (Reszkowska et al., 2011 and Gan et al., 2012). In the present study, most of the treatments exceeded $8 \%$ of AC which indicates the absence of compaction problems (Horn and Fleige, 2009), just being T1 and T2 (Figure 1a) the treatments that lowered this critical value. A similar situation was observed for pastures on a Typic Durudand (Dörner et al., 2011). 
A compaction event not only decreases the AC (Figure 1a) but also favors the creation of pores available to supply water to plants (PAW in Figure 1b), agreeing with the reports of Gan et al. (2012) and Dörner et al. (2009b and 2012). Dörner et al. (2012) clarified that this phenomenon (reduction of AC to increase PAW) is common in volcanic soils, which have allophane and high amounts of organic $\mathrm{C}$ that allow them to have a large volume of pores at different matric potentials due to the bimodal nature of the pore system (Dörner et al., 2010b). This effect, however, was not observed in the homogenized soil (T6), since aggregate destruction caused an increase in the levels of fine pores, similar to what occurs in soils with a high clay content (Armas-Espinel et al., 2003). In addition, the PAW of all treatments (Figure 1b) remained above $20 \%$, a level identified as "ideal" according to Reynolds et al. (2009).

The drying of the soil is one of the most common stresses that can affect an agro-ecosystem and is currently of great importance, because the soil as a resource will be exposed to higher hydraulic stresses due to climate change and land use change (Dörner et al., 2009a). In the case of air capacity (AC, Figure 1c), in most observed cases there was an increase in the level of this parameter (all above the critical level), although not significantly. Dörner et al. (2011 and 2012) argue that while MS destroys soil structure, HS, from the point of view of wetting and drying cycles (Peng et al., 2007, 2012), promotes soil aggregation and, therefore, the formation of macropores. This agrees with the fact that hydraulic stresses mainly affect pores of textural origin (non rigid), because their minor size makes them suffer deeply the effect of cohesion and adhesion forces between the water particles and the soil matrix (Peng et al., 2012). This happens at the expense of PAW levels, which decreased in all treatments favoring the formation of macropores (AC).
The soils under the studied pastures have great resistance and resilience capacity since most of them maintain the functions of their pores (e.g. AC and PAW) after a stressful event. These functions indicate the volume of pores available to store fluids in the soil, however, this does not indicate how accessible the fluids will be for the plants, a situation that depends on the conductive capacity of soil pores (Dörner and Horn, 2006; Reszkowska et al., 2011). This situation is coincident with the reports of Horn and Kutilek (2009) who explained and highlighted the difference between soil capacity and intensity parameters. While the first defines a general status of the soil (e.g. bulk density and water storage capacity), the second quantifies how functional soil pores (e.g. air conductivity) are. This is relevant because a soil can have a large capacity to store water and air but these fluids must be accessible to plants, a condition that might be affected by mechanical and hydraulic stresses (Horn and Kutilek, 2009).

Intensification of land use decreases the air permeability $\left(k_{a}\right)$ (Dörner et al., 2009b, 2011), which is confirmed when comparing tilled and non-tilled pastures, after both HS and MS (Figure 2a-b). After the soil was exposed to an HS, it was observed that $k_{a}$ remained the same or increased. This phenomenon is reported by Dörner et al. (2011), who compares the effect of the same kind of stress in an Andisol under native forest, a 50-year old pasture and a 1-year old pasture. In the case of T6 (Figure 2a -b), $k_{a}$ levels were very high for this type of treatment. By being a completely homogenized soil it caused the destruction of macro-aggregates, which are responsible for storing and conducting air, thus lower values were expected. These high values of $k_{a}$ can be explained by the fact that the soil of this treatment suffered a vertical and horizontal deformation, and the readjustment of the particles during the HS made them increase due to large amounts of meso and micropores present in the 
soil (Chertkov, 2013). Such types of pores leave the soil exposed to a greater shrinkage capacity because they are influenced to a greater extent by the cohesive force of water (Peng et al., 2012), which in some cases caused the soil to separate from the cylinder walls, overestimating $k_{a}$, which to some extent would simulate the formation of cracks in the soil.

Taking into account the relationship between airfilled porosity and air permeability it is possible to determine two pore continuity indices (Groenevelt et al., 1984), which indicate how functional or organized the pores are. The more functional pores (with higher continuity, Figure 3) were found in soils under nontilled pastures. However, this margin was narrow because tilled pastures had been intervened with over a year ago, suggesting that these pastures, in this type of soil, could recover part of the structure they had before being intervened with in a one-year period. Therefore, it can be expected that over time they could reach the levels of continuity of untilled pastures, highlighting the high resilience capacity of Andisols after tillage (Dörner et al., 2012). Moreover, the range of variation of $k_{2}$ and $k_{3}$ are similar to those presented by Dörner et al. (2012) who compared an Andisol under a 15-year old pasture that had been tilled, to establish a wheat crop. They found that throughout the year of the wheat crop, the connectivity of the pore system was improved due to drying and wetting cycles, which highlighted the high resilience of this type of soil. Finally, it was observed that the hydraulic stress increased slightly (non significantly) the continuity of the pores (Figure 3) as a result of the formation of cracks after the drying and wetting processes (Peng et al., 2007; Dörner et al., 2009a,b; Dörner et al., 2012; Chertkov, 2013). This effect was moderate to low, since the stress level applied did not exceed the maximum stress that the studied soil has historically suffered (at least pF 4.2 according Dörner et al., 2013a), a necessary condition to overcome the level of normal shrinkage that allows the crack formation (Peng et al., 2007; Dörner et al., 2011; Chertkov, 2013 ).

\subsection{Effect of mechanical and hydraulic stresses on the mechanical stability of the porous system}

In general, Andisols have been described as having a high shrinkage capacity (Dörner et al., 2009b), similar to that of organic soils (COLE $>0.06$ according Peng et al., 2007). The results of this study do not report values as high as those, since it only shows the shrinkage of macropores, not the total volume of soil. Mechanical stresses destroy macropores, which results in a deformation of the soil expressed as higher values of COLE in $\mathrm{C}_{2}$ (Figure $4 \mathrm{a}$ ). This may be due to the fact that by reducing the size of pores after compaction, the influence of the forces of cohesion and adhesion between the water and soil aggregates is enhanced, thus increasing the COLE of such pores. It is valid to propose that this phenomenon is characteristic of such pores and these types of soil, because the meso and micropores (data not shown) did not decrease after the stress, since there were no more pore spaces to shrink and, therefore, the sample height was stabilized. The pore size affects this behavior when facing a compaction, as proposed by Peng et al. (2007), being the pores of smaller diameter that are less susceptible to deformation by a mechanical stressful event. This can be observed if comparing all treatments versus T6, which contains smaller pores, making it impossible to decrease the height further in $\mathrm{C}_{2}$. On the other hand, not only does the size of pores affect the shrinkage of the soil, but also the type of stress to which the soil is being subjected. Therefore, according to Peng et al. (2007) a MS and a HS result in different consequences on different pore sizes, with the latter affecting the smaller pores due to the greater magnitude of influence of cohesion and adhesion 
forces between the water and soil particles. According to this, and considering that a HS is a disturbance in the soil (without considering that it promotes soil structure), the drying of the soil influences the shrinkage capacity (intensity) causing the soil to decrease its height during the determination of the first WRC $\left(C_{1}\right)$ and then stabilize in $C_{2}$. Still, there is no difference between treatments after $-80 \mathrm{kPa}$ matric potential, which is due to: i) the lack of a strong influence of the hydraulic stress on the macropores (Peng et al., 2007) and ii) the fact that the magnitude of HS (-80 kPa) did not exceed the historical level of drying for this soil (Dörner et al., 2013a), therefore, there was no large-scale rearrangement of the pore system of the soil.

The PSI, which indicates the capacity of a certain type of pore to shrink, showed lower values compared with those presented by Dörner et al. (2009a, b) for macropores (0 to - $6 \mathrm{kPa}$ matric potential) in an Andisol under 50- and 1-year old established pastures, which can be comparable with those of this study (tilled v/s non-tilled pastures). The same applies to the study of Peng et al. (2007), which also shows higher values in Eutric Histosol, Histic Gleysol and Calcic Gleysol soil types and similar values in Dystric Gleysol soil. These differences in values may be related to the organic matter content, structure type, historical management and water regime of soils in those studies.

Low values for PSI corroborate the fact that this type of pore has little capacity to shrink (Peng et al., 2007). Despite the lack of significant differences between treatments (except $\mathrm{C}_{2}$, mechanical stress), there was a clear trend showing the soil under tilled pastures had higher PSI, compared to the observations on non-tilled pastures (Figure 4b). This means that the structural phase of the shrinkage curve under the tilled pastures had greater length, because tilling breaks soil aggregates, making them larger and unstable. Later, after compaction, macro-aggregates get closer together, making the PSI increase even more, due to the increasing effect of cohesive water forces (Peng et al., 2012). The opposite occurred in T6, where macropores decreased in number and began to influence smaller pores, which have a higher shrinkage capacity in matric potential lower than -6 $\mathrm{kPa}$. For the PSI in the hydraulic stress (Figure 4d) the trend to decrease this parameter is consistent with the reports of Dörner et al. (2009b) and Peng et al. (2007). The hydraulic stress decreases the PSI by increasing the number of macropores, since structural pores are more stable for this type of stress (Peng et al., 2007; Chertkov, 2013).

COLE and PSI are parameters that register the mechanical stability of soils. Ellies et al. (1993) determined that volcanic soils have a high mechanical stability which depends, among others, on the formation of aggregates due to the interaction of mineral and organic compounds, which is also linked with the formation of roots and their architecture. In these terms, the role of roots cannot be neglected when studying the soil mechanical stability. The architecture of the root system is promoted by the absence of tillage and the soil fertilization (Glab et al., 2011). In this case, untilled pastures compared with the tilled ones presented lower values of COLE and PSI (greater mechanical stability) at the macropore level, which can be related to the formation of roots in the soil. According to Grzesiak et al. (2014), the root system architecture is affected by compaction (e.g. machinery and overgrazing). The mechanical stress of $80 \mathrm{kPa}$ (which simulates the pressure of a sheep hoof) produced a soil settlement, however, the pore system under both types of pastures (tilled and untilled) were able to maintain their functions (AC and PAW). This can be related to the soil structure formation and soil stabilization by roots (e.g. Chenu and Cosentino, 2011, Grzesiak et al., 2014), the latter being a relevant topic to be further investigated in volcanic ash soils. 
Although both types of stresses occur together in nature, they cause different impacts on the soil (Figure 5), agreeing with the observations of Peng et al. (2012), which found that MS destroyed soil structure, while the HS induced soil aggregation. Furthermore, not only does the occurrence of both stresses affect the response of the soil, but also its aggregation level, being the homogenized soils (T6) which are much more susceptible to losing their functions, which is noted in COLE. Finally, in further studies it is important: $i$ ) to separate the effect of physical resistance and resilience on soil physical functions and $i$ ) to deeply understand the role of different kinds of root systems on volcanic soil's stabilization, in order to gain a better comprehension of the impact of implementing pasture improvement techniques and grazing on soil physical functions using capacity and intensity parameters.

\section{Conclusions}

When comparing different strategies for pasture improvement, there were no substantial differences in resistance and functional recovery of soil pores against mechanical and hydraulic stresses. The lack of effect between different improvement strategies was due to the pastures being already established for a year, a situation that indicates high resistance and resilience of this type of soil, which recovered its functions to store (AC and PAW) and conduct fluids $\left(k_{a}, k_{2}\right.$ and $\left.k_{3}\right)$, after the application of both stresses. The application of higher stress levels than those that the soil was exposed to (e.g. at least hydraulic stresses of $1543 \mathrm{kPa}$ in the first $10 \mathrm{~cm}$ ), could help to improve the understanding of the effect of both kinds of stresses on soil physical functions. The destruction of soil structure during tillage (effect simulated with soil homogenization) caused a decrease in the AC lowering critical levels and an increase in soil shrinkage capacity (COLE and PSI) after compaction. Naturalized pastures showed a slightly better response against the two types of stresses when comparing tilled $\mathrm{v} / \mathrm{s}$ untilled pastures, which is related to a better and mechanically stable soil structure since the soil was not tilled.

\section{Acknowledgements}

The authors thanks the Grant FONDECYT 1100957 "Sustainable pasture improvement and its relationship to soil quality" and the contribution of the anonymous reviewers of this article.

\section{References}

Armas-Espinel, S., Hernández-Moreno, J., MuñozCarpena, R., Regalado, C. 2003. Physical properties of "sorriba" cultivated volcanic soils from Tenerife in relation to andic diagnostic parameters. Geoderma. 117. 297-311.

CIREN. 2003. Estudioagrológico X Región. Tomo $1.199 \mathrm{p}$.

Chenu, C., Cosentino, D. 2011. Microbial regulation of soil structural dynamics. In: Ritz, K., Young, I. (Eds.), The Architecture and Biology of Soils: Life in Inner Space, pp: 37-70.

Chertkov, V.Y. 2013. Shrinkage anisotropy characteristics from soil structure and initial sample/layer size. Geoderma. 200-201, 1-8.

Dec, D., Dörner, J., Balocchi. O., Lopez. I. 2012. Temporal dynamics of hydraulic and mechanical properties of an Andosol under grazing. Soil \& Tillage Reserch.125, 44-51.

Dörner, J., Horn, R. 2006. Anisotropy of pore functions in structured Stagnic Luvisols i n the weichselian moraine region in N Germany. Journal of Plant Nutrition and Soil Science. 169, 213-220. 
Dörner, J; Dec, D; Peng, X. y Horn, R. 2009a. Efecto del cambio de uso en la estabilidad de la estructura y la función de los poros de un Andisol (Typic Hapludand) del sur de Chile. Journal of Soil. Science and Plant Nutrition. 9 (3): 190-209.

Dörner, J., Dec. D., Peng, X., Horn. R. 2009b. Change of shrinkage behavior of an Andisol in southern Chile: Effects of land use and wetting/drying cycles. Soil \& Tillage Research. 106, 45-53.

Dörner, J., Sandoval, P. y Dec, D. 2010b. The role of soil structure on the pore functionality of an Ultisol. Journal Soil Science and Plant Nutrition. 10(4), 495-508.

Dörner, J., Dec, D., Zuñiga. F., Sandoval. P., Horn, R. 2011. Effect of land use change on Andosol's pore functions and their functional resilience after mechanical and hydraulic stresses. Soil and Tillage Research.115-116, 71-79.

Dörner, J., Dec, D., Feest. E., Vasquez. N., Diaz. M. 2012. Dynamics of soil structure and pore functions of a volcanic ash soil under tillage. Soil \& Tillage Research. 125, 52-60.

Dörner, J., Zúñiga, F., López, I. 2013a. Shortterm effects of different pasture improvement treatments on the physical quality of an Andisol. Journal Soil Science and Plant Nutrition. 13(2), 381-399.

Dörner, J., Dec, D., Zuñiga, F., Horn, R., López, I., Leiva, C., Cuevas, J. 2013b. Soil changes in the physical quality of an Andosol under different management intensities in southern Chile. In Krümmelbein, J., Horn, R., Pagliai, M. (Eds). Soil Degradation. Advances in Geoecology. 42, Catena Verlag GMBH Reiskirchen, Germany, pp: 262-281.
Ellies, A., Mac Donald, R., Ramirez, C. 1993 Variación en la resistencia del suelo por efecto de su uso. Turrialba. 3(1), 77-82.

Gan, L., Peng, X., Peth, S., Horn, R. 2012. Effect of grazing intensity on soil thermal properties and heat flux under Leymus chinensis and Stipa grandis vegetation in Inner Mongolia, China. Soil \& Tillage Research. 118, 147-158.

Glab, T., Kacorzyk, P. 2011. Root distribution and herbage production under different management regimes of mountain grassland. Soil \& Tillage Research. 113, 99-104.

Gregory, A.S., Watt, C.W., Griffiths, B.S., Hallet, P.D., Kuan, H.L., Whitmore, P.D. 2009. The effect of long-term soil management on the physical and biological resilience of a range of arable and grassland soil in England. Geoderma. 153, 172185.

Grzesiak, M., Ostrowska, A., Katarzyna, H., Rut, Grzegorz., Janowiak, F., Rzeptka, A., Hura, T., Grzesiak, S. 2014. Interspecific difference in root arquitecture among maize and triticale genotypes grown under drought, waterlogging and soil compaction. Acta Physiol. Plant. 36, 3249-3261.

Groenevelt, P.H., Kay, B.D., Grant, C.D. 1984. Physical assessment of a soil with respect to rooting potential. Geoderma. 34, 101-114.

Horn, R., Fleige, H. 2009. Risk assessment of subsoil compaction for arable soils in Northwest Germany at farm scale. Soil \& Tillage Research. 102, 201-208.

Horn, R., Kutilek, M. 2009. The intensity-capacity concept-How far is it possible to predict intensity values with capacity parameters. Soil \& Tillage Research. 103, 1-3. 
Krümmelbein, J., Wang, Z., Zhao, Y., Peth, S., Horn, R. 2006. Influence of various grazing intensities on soil stability, soil structure and water balance of grassland soils in Inner Mongolia, P.R. China. In: Horn R, Fleige H, Peth S, Peng X (eds) Soil management for sustainability. Advances in GeoEcology 38. Catena Verlag, Reiskirchen. 38, 93-101.

Kuan, H.L., Hallett, P.D., Griffiths, B.S., Gregory, A.S., Watts, C.W., Whitmore, A.P. 2007. The biological and physical stability and resilience of a selection of Scottish soils to stresses. European Journal Soil Science. 58, 811-821.

Peng, X., Horn, R., Smucker, A. 2007. Pore shrinkage dependency of inorganic and organic soils on wetting and drying cycles. Soil Science Society American Journal. 71, 1095-1104.

Peng, X., Zhang, Z.B., Wang, L.L., Gan, L. 2012. Does soil compaction change soil shrinkage behaviour?. Soil \& Tillage Research. 125, 89-95.
Reynolds, W.D., Drury, C.F., Tan, C.S., Fox, C.A., Yang, X.M., 2009. Use of indicators and pore volume-function characteristics to quantify soil physical quality. Geoderma. 152, 252-263.

Reszkowska, A., Krümmelbein, J., Zhao, Y., Peth, S., Horn, R., Gan, L. 2011. Influence of grazing on hydraulic and mechanical properties of semiarid steppe soils under different vegetation type in Inner Mongolia, China. Plant and Soil. 340, 5972.

Soil Survey Staff, 2006. Keys to Soil Taxonomy, 10th ed. Agric. Handbk., 436. NRCS, Washington DC.

Zuñiga, F., Ivelic-Sáez, J., López, I., Huygens, D., Dörner, J. 2015. Temporal dynamics of the physical quality of an Andisol under a grazing system subjected to different pasture improvement strategies. Soil \& Tillage Research. 145, 233-241.

Zhang, B., Horn, R., Hallett, P.D. 2005. Mechanical resilience of degraded soil amended with organic matter. Soil Science Society American Journal. 69, 864-871. 